\title{
Students' Performance on Cognitive, Psychomotor and Affective Domain in the Course Outcome for Embedded Course
}

\author{
Nur Asmaliza Mohd Noor*, Noraida Mohd Saim, Rohaya Alias, Siti Hawa Rosli \\ Faculty of Civil Engineering, Universiti Teknologi MARA Pahang, Malaysia
}

Received April 26, 2020; Revised June 2, 2020; Accepted June 26, 2020

Copyright $\bigcirc 2020$ by authors, all rights reserved. Authors agree that this article remains permanently open access under the terms of the Creative Commons Attribution License 4.0 International License

\begin{abstract}
The role of higher education is creating a holistic education for the students by integrating all learning domains, such as cognitive, psychomotor and affective into the course. The study aimed to investigate the students' performance on cognitive, affective and psychomotor domains according to the given assessment for embedded courses, which are Basic Soil Mechanics and Basic Hydraulics for the Diploma in Civil Engineering programme. There were 336 students of Basic Hydraulics and 406 students of Basic Soil Mechanics involved in this study. The assessments for the embedded courses are through $60 \%$ of the cognitive domain, $30 \%$ of the psychomotor domain and $10 \%$ of the affective domain. Simple frequency counts and Spearman's rank-order correlation were used to analyse students' performance. The results indicated that the students performed better in the psychomotor and affective domain compared to the cognitive domain. Meanwhile, the Spearman analysis showed that the Basic Hydraulic and Basic Soil Mechanics presented positive correlation, $r=0.039$ and $r=0.268$ respectively $(\alpha=0.05)$. The overall assessment incorporating all learning domains for each course is essential to produce skilled and knowledgeable graduates from any higher education programmes to meet industry needs.
\end{abstract}

Keywords Affective, Cognitive, Learning Domain, Psychomotor, Embedded Course, Students' Performance

\section{Introduction}

The Engineering Technology Accreditation Council 2019 Manual requires specific programme outcomes of engineering academic programmes to produce graduates with positive attributes such as having an excellent practical skill, able to communicate well and work in a team [1]. To achieve these intentions, psychomotor and affective domains from Bloom's Taxonomy need to be applied [2]. In sum, the cognitive domain is more on thinking skills, psychomotor is more on hands-on and practical skills while the affective domain is more on communication and teamwork. Bloom's taxonomy provides a consistent means of developing the assessment of students based on program outcomes (PO) where it can motivate the educators to focus on all the domains, thus creating a more holistic form of education. To be specific, Table 1 describes each level of the previously mentioned domains.

The cognitive domain is easy to measure compared with the other two domains. It is measured through the final examination with the allocation of around $20-35 \%$ from the total marks of the question paper that should achieve the higher-order cognitive levels [3]. A student, who can answer the higher (C5 and C6) cognitive level questions, indirectly shows that the particular student can achieve the affective and psychomotor domains. However, all the domains should follow the distribution percentage (Table 2, 3 and 4) to identify the performance of students, who should deserve to be excellent students. 
Table 1. Levels for cognitive, psychomotor and affective domain [2].

\begin{tabular}{|l|l|}
\hline Domain & \multicolumn{1}{|c|}{ Level } \\
\hline \multirow{5}{*}{ Cognitive } & The cognitive domain carries studying capabilities predominantly associated with the questioning \\
methods. The cognitive domain includes a hierarchy of skills involving processing information, \\
constructing understanding, applying knowledge, solving problems and conducting. There are six \\
levels of cognitive complexity which are; \\
C1: Knowledge \\
C2: Comprehension \\
C3: Application \\
C4: Analysis \\
C5: Synthesise \\
C6: Evaluation \\
\hline The psychomotor domain is a domain that utilise skills, how to coordinate them and relates to the \\
& physical encoding of information with movement and or with activities. There are six categories \\
& under this area such as \\
& P 1: Perception \\
& P 2: Set \\
& P 3: Guided response \\
& P 4: Mechanism \\
Psychomotor & The Complex overt response \\
\hline \multirow{5}{*}{ Affective } & we deal with things emotionally such as feelings, values, appreciation, enthusiasm, motivation and \\
& attitudes. This domain is categorised into five sub-domains which include \\
& A 1: Receiving \\
& A 2:Responding \\
& A 3: Valuing \\
& A 4:Organization \\
A 5:Characterization
\end{tabular}

Table 2. Distribution Percentage for Cognitive Domain

\begin{tabular}{|c|c|c|c|c|c|c|}
\hline Year & C1 (Knowledge) & C2 ( Comprehension) & C3 (Application) & C4 (Analysis) & C5 (Synthesis) & C6 (Evaluation) \\
\hline 1 & \multicolumn{2}{|c|}{$30-45$} & \multicolumn{2}{|c|}{$25-45$} & \multicolumn{2}{|c|}{$10-25$} \\
\hline 2 & \multicolumn{2}{|c|}{$20-35$} & \multicolumn{2}{|c|}{$40-60$} & \multicolumn{2}{|c|}{$20-35$} \\
\hline 3 & \multicolumn{2}{|c|}{$10-25$} & \multicolumn{2}{|c|}{$45-55$} & \multicolumn{2}{|c|}{$30-45$} \\
\hline
\end{tabular}

Table 3. Distribution Percentage for Affective Domain

\begin{tabular}{|c|c|c|c|c|c|}
\hline Year & A1 (Receiving) & A2 (Responding) & A3 (Valuing) & A4 (Organising) & $\begin{array}{c}\mathrm{A} 5 \\
\text { (Characterisation) }\end{array}$ \\
\hline 1 & \multicolumn{2}{|c|}{$30-45$} & \multicolumn{2}{|c|}{$25-45$} & $10-25$ \\
\hline 2 & \multicolumn{2}{|c|}{$20-35$} & \multicolumn{2}{|c|}{$40-60$} & $20-35$ \\
\hline 3 & \multicolumn{2}{|c|}{$10-25$} & \multicolumn{2}{|c|}{$45-65$} & $30-45$ \\
\hline
\end{tabular}

Table 4. Distribution Percentage for Psychomotor Domain

\begin{tabular}{|c|c|c|c|c|c|}
\hline Year & P1 (Perception) & P2 (Set) & P3 (Guided Response) & P4 (Mechanism) & P5 (Complex over response) \\
\hline 1 & \multicolumn{2}{|c|}{$30-45$} & \multicolumn{2}{|c|}{$45-65$} & $10-25$ \\
\hline 2 & \multicolumn{2}{|c|}{$20-35$} & \multicolumn{2}{|c|}{$40-60$} & $20-35$ \\
\hline 3 & \multicolumn{2}{|c|}{$10-25$} & \multicolumn{2}{|c|}{$45-55$} & $30-45$ \\
\hline
\end{tabular}

Students should acquire a broad and critical knowledge, including the understanding of methods and techniques and also the knowledge of the subject. It is to ensure the students are able to synthesis the concept rationally and solve the problems through unrestrained approach [4]. Meanwhile, practical hands-on is an opportunity to develop competency and skill in learning to investigate and solve the problem [5]. A study conducted by Schuijers [6] on physiology students explained that the students who undertake an embedded course seem able to develop skills in problem-solving and deeper understanding rather than taking the theory course alone. According to Standal [7], the practical experience that is introduced by the university through the academic courses indicates the improvement in the students' performance. Hairuddin [8] presented that embedded courses greatly influence the achievement of culinary arts students. The culinary arts students cannot achieve a good performance if they only show cooking 
skills, but are unable to think, understand and apply.

To date, there are only a few studies [5],[6],[7],[8] and [9] discussed on the effectiveness of embedded courses in non-civil engineering courses. Hence, there is a necessity to conduct a study on the students' performance on the cognitive, psychomotor and affective domains in civil engineering courses since the embedded course is treated differently in the university.

Therefore, this paper aims to evaluate the performance of students according to the domain levels. Furthermore, it is also intended to assess whether the assessment of coursework which is dominated by psychomotor and affective domains correlate or not with the cognitive domain, which comes from the final examination.

\subsection{Description of the Courses}

There are two courses involved in this study, namely Basic Hydraulics and Basic Soil Mechanics. These courses were taken by students' in semester four (4), designed and embedded with laboratory work. Both courses have the allocation of these three (3) domains where $60 \%$ comes from the cognitive level, $30 \%$ from the practical test (psychomotor) and $10 \%$ from laboratory observation (affective). Basic Hydraulics is a course that deals with the fundamental in Fluid Mechanics, and the students need to understand the behaviour of fluids through the study of water flow in various civil engineering applications. Meanwhile, the Basic Soil Mechanics deals with the principles of soil mechanics, and it covers the topic on physical properties and classification of soil, shear strength, the flow of water through soil, soil compaction and consolidation. This course also provides exposure for students on procedures to perform standard laboratory tests for the soil in various civil engineering purposes.

\subsection{Planning Stage for Cognitive, Psychomotor and Affective}

\subsubsection{Delivery Method}

Since those subjects were a combination of three domains, they have different types of delivery methods. The cognitive domain is delivered through the lecture sessions. The instructor discussed on the related topics as proposed in the syllabus within 3 hours for 14 weeks. Meanwhile, the delivery method for the psychomotor and affective domains are through the laboratory session. It is conducted 2 hours per week for 14 weeks.

\subsubsection{Assessment and Evaluation}

The evaluation for the cognitive level was through the 3 hours of the final examination. There are around 10-11 questions designed according to the percentage of distribution for each cognitive level, as shown in Table 2. The assessments for the affective domain are conducted in week 4 , week 8 and week 12 . The aim is to evaluate the behaviour of each student when they experimented. The instructors follow the designated rubrics which fulfills each affective level and is based on the percentage of distribution for the affective domain, as shown in Table 3, to assess the students' performance.

Meanwhile, for the psychomotor domain, the assessment is held in week 7 and week 14. The test is conducted in week 7 and is named as practical test 1 and the test conducted in week 14 is named as practical test 2 . The experiments that are covered in practical test 1 are the experiments conducted from week 1 until week 6 . Practical test 2 included the experiments conducted from week 8 until week 13. The evaluations for these two tests are based on how the student performed on the given experiment individually and are assessed by the instructor using the specific rubrics for each psychomotor level and are based on the distribution of marks, as stated in Table 4 .

\subsection{Research Questions}

The research questions of this study to achieve the objectives are as follows;

i. What is students' performance according to the cognitive, psychomotor and affective domains for embedded courses?

ii. Is there any correlation between cognitive, psychomotor and affective domains according to the students' performance.

\section{Materials and Methods}

These courses are designed for Year 2 of an engineering diploma course in a public university. The examination results of 336 students of Basic Hydraulics and 406 students of Basic Soil Mechanics were analysed, and the selection of the students was based on those who registered for the courses. The students' performance was graded based on the marks obtained through the following; Cognitive (60\%), Psychomotor (30\%) and Affective (10\%) and the indicator of the performance can be seen through the scoring guide presented in Tables 5, 6 and 7 respectively. Furthermore, the descriptive statistical analysis involving simple frequency counts of the score was applied to assess the students' performance.

Table 5. Scoring guide of percentage marks obtained for Cognitive Domain

\begin{tabular}{|c|c|}
\hline $\begin{array}{c}\text { Percentage Marks Obtained for } \\
\text { Cognitive domain }\end{array}$ & Remarks \\
\hline $50-60$ & Excellent \\
\hline $40-49.9$ & Very Good \\
\hline $30-39.9$ & Good \\
\hline $20-29.9$ & Fair \\
\hline $10-19.9$ & Poor \\
\hline $0-9.9$ & Very Poor \\
\hline
\end{tabular}


Table 6. Scoring guide of percentage marks obtained for Psychomotor Domain

\begin{tabular}{|c|c|}
\hline $\begin{array}{c}\text { Percentage marks obtained for } \\
\text { Psychomotor work }\end{array}$ & Remarks \\
\hline $25-30$ & Excellent \\
\hline $20-24.9$ & Very Good \\
\hline $15-19.9$ & Good \\
\hline $10-14.9$ & Satisfactory \\
\hline $5-9.9$ & Poor \\
\hline $0-4.9$ & Very Poor \\
\hline
\end{tabular}

Table 7. Scoring guide of percentage marks obtained for Affective Domain

\begin{tabular}{|c|c|}
\hline $\begin{array}{c}\text { Percentage marks obtained for } \\
\text { affective work }\end{array}$ & Remarks \\
\hline $8-10$ & Excellent \\
\hline $6-7.9$ & Good \\
\hline $4-5.9$ & Satisfactory \\
\hline $2-3.9$ & Poor \\
\hline $0-1.9$ & Very Poor \\
\hline
\end{tabular}

Additionally, the statistical analysis using Spearman's rank-order correlation coefficient was used to identify the correlation between students' performance in each domain. The results indicated a positive correlation between students' performance in each domain if the Spearman's rank-order between $-1<=\mathrm{r}<=1 ;-1$ demonstrates strong negative correlation, 0 demonstrates no correlation and 1 demonstrate a strong positive correlation.

The results obtained through Spearman's correlation coefficient should be able to fulfil one of the following hypotheses:

$\mathrm{H}_{0}$ : There is no correlation between cognitive, psychomotor and affective domain which was obtained by the students for ECW321

$\mathrm{H}_{0}$ : There is no correlation between cognitive, psychomotor and affective domain which was obtained by the students for ECG303

$\mathrm{H}_{1}$ : There is a correlation between cognitive, psychomotor and affective domain which was obtained by the students for ECW321

$\mathrm{H}_{1}$ : There is a correlation between cognitive, psychomotor and affective domain which was obtained by the students for ECG303.

\section{Results and Discussions}

The assessment of the cognitive domain was calculated from the final exam marks because the cognitive domain involves knowledge, comprehension, application of the theory, and the analytic skill to solve the problems given. The final exam questions were designed based on a different cognitive level. Figure 1 shows the distribution of the student's achievement based on the scoring guide and marks attained. The performance for ECG303; most of the students (38.67\%) achieved good marks which ranged between 30 to 39 , but only $1.97 \%$ of the students were able to get excellent marks, while another $20.44 \%$ attained a very good score. As for ECW321, most of the students $(51.19 \%)$ achieved marks in the range of $20-29.5$ which falls under the category of fair, and only $0.3 \%$ attained excellent marks. There is a different trend of findings between ECG303 and ECW321 because students were unable to answer very well for ECW321 compared to ECG303. They did not grasp the knowledge and fundamentals that were applied in ECW321 compared to ECG303. Moreover, the nature of the subjects is different where ECW321 is more on application, while ECG303 is more on fundamental knowledge. On the other hand, this result to some extent varies with the findings by Antoni [9] where the students score higher marks in the final exam when they enrolled in embedded subjects.

In the meantime, Table 8 shows the coefficient values from the analysis using Spearman's correlation and descriptive analysis result.

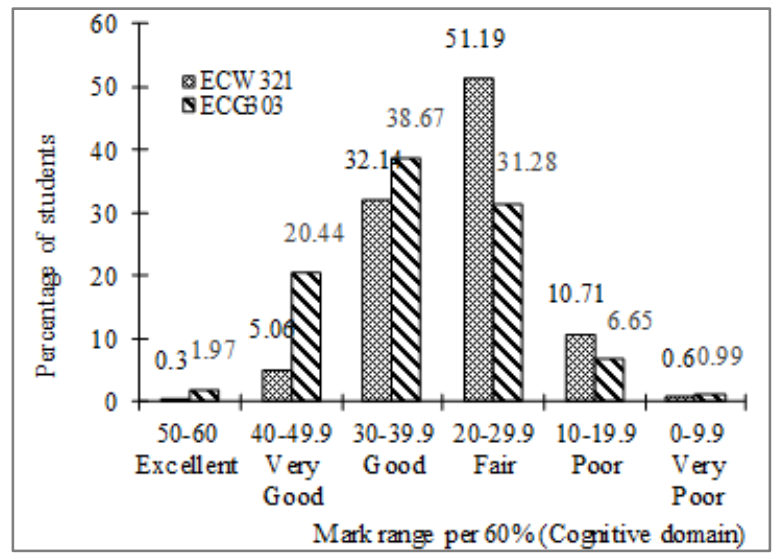

Figure 1. Cognitive domain attainment for ECG 303 and ECW321

Table 8. Statistical analysis for ECG303 and ECW321

\begin{tabular}{|c|c|c|c|c|}
\hline \multicolumn{2}{|c|}{ Subject } & Mean & $\begin{array}{c}\text { Standard } \\
\text { Deviation }\end{array}$ & Correlation \\
\hline \multirow{2}{*}{ ECW321 } & Final Exam & 22.57 & 6.587 & \multirow{2}{*}{0.039} \\
\cline { 2 - 4 } & Coursework & 32.53 & 3.29 & \\
\hline \multirow{2}{*}{ ECG303 } & Final Exam & 31.59 & 9.06 & \multirow{2}{*}{0.268} \\
\cline { 2 - 4 } & Coursework & 32.88 & 2.83 & \\
\hline
\end{tabular}

The mean value for both courses indicated the higher mean value (31.59) for ECG303 final exam compared to the mean value (22.57) for ECW321 final exam. Nevertheless, they have similar mean value for coursework, and both have low standard deviations which indicates that most students obtained the marks of the coursework close to the mean value as shown in Table 8. The Spearman analysis showed the Basic Hydraulic and Basic Soil Mechanics presented positive correlations, $\mathrm{r}=0.039$ and 
$\mathrm{r}=0.268$ respectively $(\alpha=0.05)$ which showed that the increased marks obtained by the students for the cognitive domain are interrelated with the increased marks obtained by the students for the psychomotor and affective domains. Hence, it can be summarised that the cognitive, psychomotor and affective domains are correlated. The findings seem to agree with the study conducted by Chowdhry [10], which showed the correlation between the final marks and coursework marks attained by the students.

In the civil engineering course, students' ability in integrating theory and practise is an important learning objective to achieve as stated in the Outcome-Based Education. Similarly, to fulfil the requirements of the Engineering Technology Accreditation Council, students should be able to develop competency in executing experimental work [1]. This is agreed by Lai, [11] through the various measurements on the students' performance which indicated that the students performed better through the written examination, instructor's observation and peer evaluation.

Previously, the written technical report was the only method to assess the laboratory skill. However, depending only on the written report is not enough to assess the students' ability to perform specific laboratory activities such as setting up the equipment and demonstrate the experiment according to the right procedure. Thus, the practical skill assessment was introduced to evaluate students' performance demonstrating the laboratory activities.

Assessment of the physical actions of the engineering students in laboratory works is categorised in the psychomotor domain. Specific rubrics of different levels are used as a reference to grade the students. This exercise is part of the coursework that carries $30 \%$ of the total final marks. Table 9 shows the proportion of the achievement in the practical tests based on the range of marks; $57 \%$ of the students for ECG303 and 50\% of the students for ECW321 were excellent in conducting laboratory works by following the correct procedure, understand the purpose and are able to predict the outcome from the experiment. In the meantime, the practical tests could provide students with hands-on experience and the ability to visualise the actual scenario related to design calculation that are learned through the lecture sessions [12].

Table 9. Psychomotor Domain attainment for ECG 303 and ECW321

\begin{tabular}{cccc}
\hline Scoring guide & $\begin{array}{c}\text { Range } \\
\text { Marks }\end{array}$ & $\begin{array}{c}\text { ECG303 } \\
\text { Percentage } \\
\mathbf{( \% )}\end{array}$ & $\begin{array}{c}\text { ECW321 } \\
\text { Percentage } \\
(\%)\end{array}$ \\
\hline Very poor & $0-4.9$ & 0.00 & 0.00 \\
\hline Poor & $5-9.9$ & 0.00 & 0.00 \\
\hline Satisfactory & $10-14.9$ & 0.25 & 1.19 \\
\hline Good & $15-19.9$ & 1.72 & 8.04 \\
\hline Very good & $20-24.9$ & 41.13 & 39.88 \\
\hline Excellent & $25-30$ & 56.90 & 50.00 \\
\hline
\end{tabular}

In the affective domain, the instructors observed the students during the laboratory sessions to access the student's attitude; such as dealing with discipline awareness including the attendance, participation and cooperation in a group, time management while conducting laboratory work and the organisation within the group. The assessment of the affective domain is based on the specific rubrics to guide the instructors. Johnson [13] described that the presence of students in the academic class session was a conscious decision made based on their beliefs and attitude to expand their knowledge. It is also as an indicator of participation when they committed their time and energy to attend the learning activities. Table 10 presents the findings that show the students have good and excellent attitude during the laboratory sessions (100\% for ECG303 and $98.81 \%$ for ECW321). These indicated that they appreciated the experience while conducting the experiments and focused on executing the laboratory work.

Table 10. Affective Domain attainment for ECG 303 and ECW321

\begin{tabular}{cccc}
\hline $\begin{array}{c}\text { Scoring } \\
\text { guide }\end{array}$ & $\begin{array}{c}\text { Range } \\
\text { Marks }\end{array}$ & $\begin{array}{c}\text { ECG303 } \\
\text { Percentage (\%) }\end{array}$ & $\begin{array}{c}\text { ECW321 } \\
\text { Percentage (\%) }\end{array}$ \\
\hline Very poor & $0-1.9$ & 0.00 & 0.30 \\
\hline Poor & $2-3.9$ & 0.00 & 0.00 \\
\hline Satisfactory & $4-5.9$ & 0.00 & 0.89 \\
\hline Good & $6-7.9$ & 56.16 & 21.13 \\
\hline Excellent & $8-10$ & 43.84 & 77.68 \\
\hline
\end{tabular}

In comparing the domains attainment, the overall findings clearly show that the student's performance is better in the psychomotor and affective domains. Perhaps it is because of the level in the cognitive domain that requires students to genuinely understand the concept of the theory, not just memorize it to answer the final exam question. With a strong fundamental knowledge of the theory, students should be able to analyse the problem given in the question, then evaluate the right solution or equation to use for solving the problem.

Additionally, the laboratory experiments should be designed based on the design calculation topic to help them to understand further. Thus, this can help to develop their engineering application skills [10]. Learning activities in both theoretical and experimental studies are encouraged to expose students into more in-depth learning approach in the environment of the courses taught [5].

\section{Conclusions}

The study revealed that learning domains influence students' performance. The students' performance for psychomotor and affective domains in both courses is better than the cognitive domain. The reason is the students lack understanding the concepts and methods to respond to the final exam questions since there are no tests, quizzes or assignments in the coursework assessment. They have no 
experience in dealing with any kind of cognitive domain coursework assessment.

The primary domain in the learning system is the cognitive domain. Hence, the distribution of assessment marks has a more significant impact compared to the other domains. The cognitive domain is much easier to determine in contrast to the psychomotor and affective domains. Typically, the assessment for this domain is by an examination. Whereas the achievement of the psychomotor domain was measured by carrying out practical laboratory tests, and the measurement of the affective domain was attained through lab observations. To ensure the consistency of each evaluation, the use of the same rubrics by the different instructors is significant in assessing the psychomotor and affective domains of students.

The comprehensive assessment in the courses is prominent in providing graduates who can apply the theory and skill in the academic courses. Therefore, to improve student achievement in the cognitive domain for laboratory-embedded courses, the current assessment method can be modified. The test or assignment should be included in the coursework assessment. In addition, the students' achievement of cognitive, affective and psychomotor domains should be balanced to meet the requirements of the industry where they are working.

\section{Acknowledgments}

The authors would like to express their gratitude to the students who directly involved in this study and to the people who indirectly involved as well.

\section{REFERENCES}

[1] Board of Engineer Malaysia (BEM). (2019). Engineering Technology Accreditation Council Manual 2019. Online available from http://etac.org.my/wp-content/uploads/2018/ 10/Engineering-Technician-Education-Programme-Accredi tation-Standard-2019.pdf

[2] B.S. Bloom. Taxonomy of educational objectives: The classification of educational goals, Handbook 1: Cognitive domain, New York: Longman,1956

[3] N. A. M. Noor, K. Ariffin and A. Alias. Examining Students' Readiness for Higher Cognitive Level Questions: A Case of
Hydraulic Engineering Students, 2018 IEEE 10th International Conference on Engineering Education (ICEED), Kuala Lumpur, Malaysia, 79-82, 2019.

[4] W.C. Kyle Jr. The Distinction Between Inquiry and Scientific Inquiry and Why High School Students Should Be Cognizant of the Distinction, Journal of Research on Science Teaching 17, 123-130,1980

[5] P. Kirschner. Epistemology, practical work and academic skills in science education. Science Equation 1, 273-299, 1992

[6] J.A. Schuigers, J.S. Mc Donalds, B.L. Julien, L.A. Lexis, C.J. Thomas, S. Chan, T. Samiric. The effectiveness of separating theory and practicum as a conduit to learning physiology. Advances in Physiology Education 37, 153-156, 2013

[7] O.F. Standal, K.M. Moen, V.F. Moe. Theory and practice in the context of practicum: The perspectives of Norwegian physical education student teachers. European Physical Education Review 20(2), 165-178, 2013

[8] H. Hairuddin, A.R. Abdul Wafi, A.S. Noorazman, M.N. Siti Noor Fazelah, M.S. Adibah Aishah. The effectiveness of cognitive and psychomotor domain of culinary art students' performance after internship in private colleges. MATEC Web of Conferences, Penang, Malaysia, 1-4, 2018

[9] P. Antoni, S.C. Fermin, S. Nuria, L. David. Cooperative learning and embedded active learning methodologies for improving students' motivation and academic results. International Journal of Engineering Education 35(6A), 1-8, 2019

[10] S. Chowdhry. Investigating the effect of theoretical and laboratory teaching on the students' academic performance in Mechanical Engineering. Journal Today's Idea-Tomorro w's Technology Vol 3, No 1, 53-72,2 015

[11] E.R. Lai. Creating curriculum-embedded, performance based assessments for measuring 21 st century skills in $\mathrm{K}-5$ students. Vancouver, B.C.: American Educational Research Association, April 2012

[12] J. Bertram. Hypothesis testing as a laboratory exercise: a simple analysis of human walking, with a physiology Surprise, Advance Physiology Education 26: 110-119, 2002.

[13] F. Johnson. Measuring Outcomes of Students' Learning Involving the Learning Modalities, Domains, Critical Thinking Skills Levels, and Right-and Left-Brain Thinking. Tenth Annual College of Career Education Faculty Symposium on Teaching Effectiveness, 18-38, October 2002. Retrieved from: https://commons.erau.edu/cgi/viewc ontent.cgi? article $=1117 \&$ context $=$ bollinger-rosado 